Egypt. Acad. J. biolog. Sci., 3 (1): 173 - 184 (2010)

Email: egyptianacademic@yahoo.com

Received: 29/6 /2010
A. Entomology

ISSN: 1687-8809

www.eajbs.eg.net

\title{
Variability in head shapes in three populations of the Rice Bug Leptocorisa oratorius (Fabricius) (Hemiptera: Alydidae)
}

\author{
Mark Anthony J. Torres; Jade Lumansoc, and Cesar G. Demayo* \\ Department of Biological Sciences, College of Science and Mathematics, \\ Mindanao State University-Iligan Institute of Technology, \\ 9200 Iligan city, Philippines \\ *For Correspondence: cgdemayo@gmail.com
}

\begin{abstract}
The rice bug, Leptocorisa oratorius (Fabricius) is an insect pest of rice that feeds on developing rice grains reducing the yield and quality of rice. Identification of this pest has been vague owing to variability in its external morphological characteristics. It has been referred to as L. acuta (Thunberg) and L. varicornis in some literature. In this study, the shapes of the head capsule were compared in populations of the rice bug using a landmark-based geometric morphometric method, and analysis of relative warp scores. Samples were collected from three different localities of which eighty-three were from Alubijid, Misamis Oriental; nineteen from Maigo, Lanao del Norte; and eighty-two from Buug, Zamboanga Sibugay. Of the 184 individuals, 116 were classified as males and 68 were classified as females. Images of the dissected head capsule was acquired with the use of MacronCam and Leica ES2 microscope. Landmark analyses was done on the $\mathrm{x}$ - and $\mathrm{y}$ - coordinates of the head outline which totalled to 35 landmark points. The results showed variability within and among populations of the rice bugs in the regions at the labrum, vertex, and the outline of the compound eye insertion. This variability may represent unique genotypes and that this geographic variation may have an important effect on expanding population sizes in following years which should be considered in control methods.
\end{abstract}

Keywords: Leptocorisa oratorius (Fabricius), Geometric Morphometrics, Relative Warps Analysis, Canonical Variate Analysis, Discriminant Function Analysis.

\section{INTRODUCTION}

With the continued increases in the human population and losses of arable land, there is a need to increase rice production per unit of land through development of rice production strategies that are sustainable and are economically, environmentally, and socially acceptable (Heinrichs, 1994). However, insects are a major constraint in the production of rice throughout the world. They are especially severe in tropical Asia and are increasing in importance in Africa and South America. One of the most important rice bugs in the subtropical and tropical rice areas belong to the genus Leptocorisa. Rice bugs concentrate on small-scale upland rice fields that they can actively search out. The lowland rice crops of Asia are dominated by Leptocorisa oratorius (Fabricius) (Pathak and Khan, 1994; Dale, 1994; Jahn et al., 2004, Panizzi et al., 2000; Kay et al., 1993). The feeding habits of adults and nymphs are similar. The insects live on grasses but prefer flowering rice. Growing rice bug nymphs are more active feeders than adults, but adults cause more damage because they feed for a longer period. Grains damaged during milk stage remains empty. Injury during the milk stage causes yield loss; damage during the dough stage impairs 
grain quality. Since rice is the staple food of most Asians, there is a need to control or manage populations of this pest but many times this species has been misidentified in literature as L. acuta (Thunberg), L. acuta Stal, or L. varicornis F. owing to close resemblances among these species (Jahn et al., 2004). There is, therefore, a need to have more studies that will describe the amount of diversity within, between and among these rice pests. Distinct populations of agronomic pest sometimes differ only on minute phenotypic characters. Sometimes, these characters are often seen associated with virulence and may represent stable characters with genetic bases, thus are good bases for the study. We applied the tools of geometric morphometrics (GM) to be able to describe phenotypic diversity in the species of $L$. oratorius.

Advances in GM have provided supplemental data on size and shape variation in biological structures that, added to traditional morphological features and molecular characters, helped in establishing reliable criteria to determine population differentiation in important agronomic pests. Geometric morphometrics have been found to be an indispensable technique in the identification of species and in quantifying the nature of morphological variation (Losos, 1990; Ricklefs and Miles, 1994) within a species (Caley et al., 1995; Conde-Padin et al., 2007). Unlike analytical approaches, the geometric one is aimed at a comparison of shapes themselves. By quantifying morphological variation, it is easier to identify the relationship between morphology and ecology (Losos, 1990; Ricklefs and Miles, 1994) and thus make additional informed inferences on the evolution of pest organisms (Adams, 1999). Since the head is associated with feeding preferences, this study was therefore conducted in this structure to determine patterns of variation within and among populations of the rice bug, L. oratorious.

\section{MATERIAL AND METHODS}

Collecting and preparation of samples. Specimens were sampled from rice fields in two different localities in Mindanao, Philippines namely Alubijid, Misamis Oriental and Buug, Zamboanga Sibugay (see Fig. 1). Collecting was done by sweeping the insect net back and forth throughout the rice paddy. A total of 184 specimens were collected consisting of 116 males and 68 females.

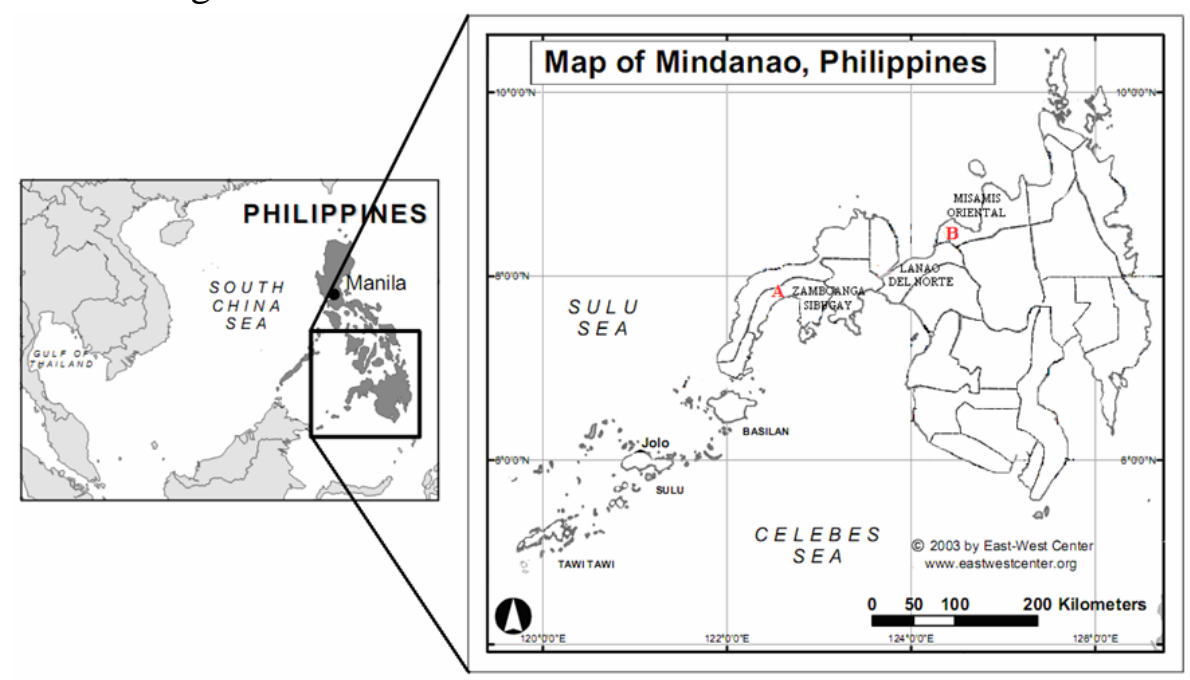

Fig. 1: Geographical presentation of the different sampling sites with their boundaries. (A) Buug, Zamboanga Sibugay, (B) Maigo, Lanao del Norte, and (C) Alubijid, Misamis Oriental. Source: www.eastwestcenter.org. 


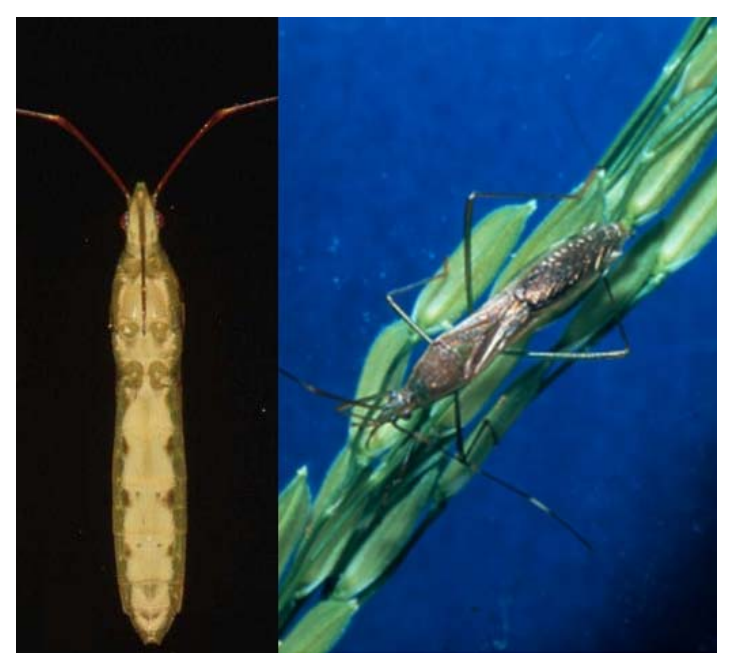

Fig. 2: Habitus (right) and ventral image of Leptocorisa oratorius (Fabricius) (left) showing the marked ventro-lateral spots. Source: Jahn et al. 2004.

Prior to dissection, specimens were identified up to the species level wherein it was identified as Leptocorisa oratorius (F.) (Fig. 2). L. oratorius can be easily identified with the presence of ventrolateral spots on the abdomen (Barrion and Litsinger, 1998). The samples were then segregated to sexes by inspection of the genital plate. Using forceps, the samples were then dissected removing the head capsule. Image was then captured from the structure using a Leica ES2 microscope with a MacronCam attached to its eyepiece.

\section{Data Acquisition}

Landmark assignments. Two-dimensional Cartesian coordinates of 35 landmarks were digitized by tpsDig ver.2 software (Fig. 3) (Rohlf, 2004). In order to reduce the measurement error, all specimens were digitized with three replicates (Dvorak et al., 2005). This software facilitated to obtain $\mathrm{x}$ and $\mathrm{y}$ coordinates of the landmark points which are the raw data used for further analysis. The landmark configurations obtained were then scaled, translated, and rotated against the consensus configuration by GLS (General Least Squares) Procrustes superimposition method (Bookstein, 1991; Rohlf and Marcus, 1993; Dryden and Mardia, 1998).

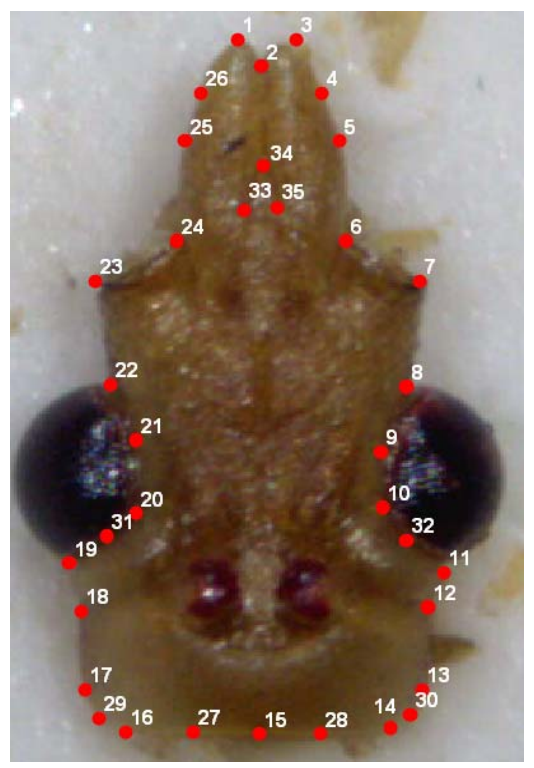

Fig. 3: Designated landmarks and pseudolandmarks of the head capsule. 
Relative warps analysis. The relative warps analysis (Bookstein, 1991) was performed using the tpsRelw version 1.46 (Rohlf, 2008). Relative warps analysis corresponds to a Principal Components analysis of the covariance matrix of the partial warp scores, which are different scales of a thin-plate spline transformation of landmarks (Frieß, 2003). According to Hammer et al. (2001), usually the most informative are the first and second relative warps.

Thin-Plate Splines. Thin-plate splines was used in order to graphically illustrate patterns of shape variations based on the landmarks which represents the transformation of the reference to each specimen (Bookstein, 1991). From the reference configuration, the principal warps were calculated to define a set of coordinate axes for tangent space approximating the curved shape space to which the shapes of specimens can be compared using standard linear statistical methods. The $\mathrm{x}$ and $y$ - coordinates of the aligned specimens onto the principal warp axes are then projected.

Male and female datasets were pooled and was analyzed using canonical variate analysis to determine variation among groups as expressed relative to the pooled within-group variation. CVA was used in order to compare patterns of interspopulation variation.

Multivariate analysis was done using the Palaeontological Statistics (PAST) software (Hammer et al., 2001). As a form of multivariate measure, the Wilk's lambda would determine the relationship between several variables.

Discriminant Function Analysis. In this test, the discriminant analysis was used to show whether the observed variation in head capsule shapes between the two populations of rice bug is statistically significant.

\section{RESULTS AND DISCUSSION}

CVA scatter plots of the pooled individuals from the two populations of the rice bugs showed similar patterns of intrapopulation variation (Fig. 4). Sexual dimorphism was observed in head shapes for both populations.
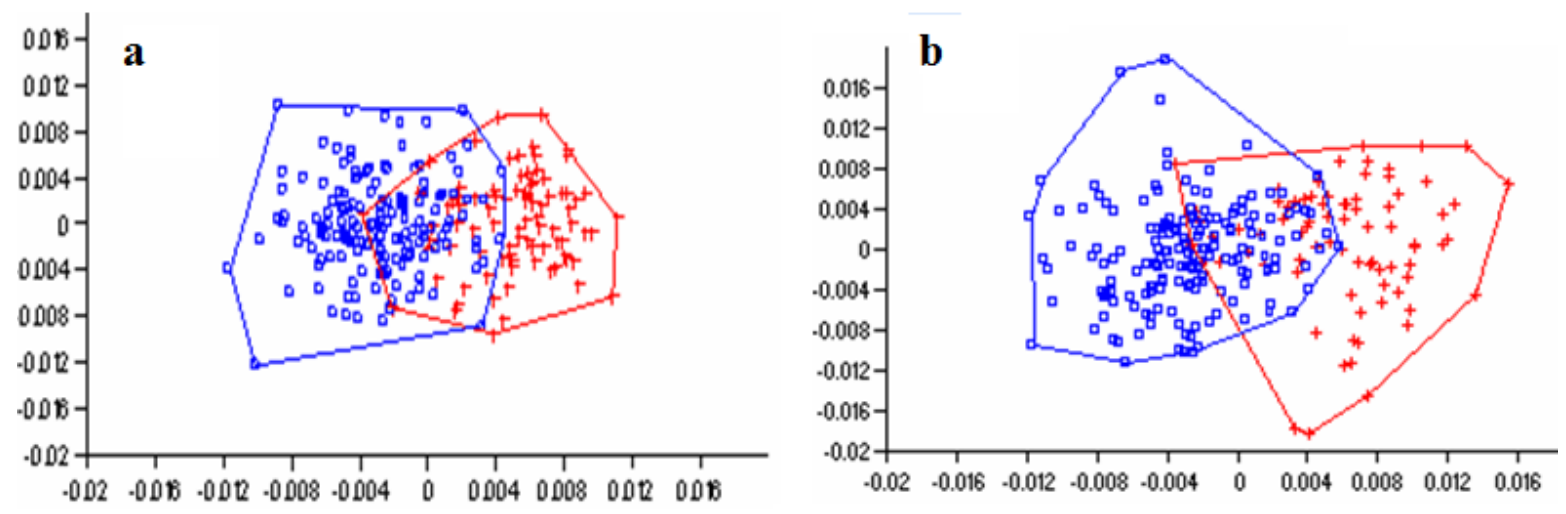

Fig. 4: CVA scatter plot of the pooled individuals of the rice bug, Leptocorisa oratorius showing the male (square) and female (cross) individuals from (a) Alubijid, Misamis Oriental and (b) Buug, Zamboanga Sibugay.

Table (1) and Figures (5-7) show the summary of the head shape variation among the three populations of the rice bugs investigated. Variability was observed in the shape of the labrum, vertex, and the concavity where the outline of the compound 
eye is located. Minimal variations are also seen in the insertion of the antennal joint (Fig. 4).

Table 1. Descriptions of the head shapes as shown by the relative warps.

\begin{tabular}{|c|c|c|c|c|c|c|}
\hline$\overline{\mathrm{FW}}$ & \multicolumn{6}{|c|}{ POPTLATIOKE } \\
\hline & \multicolumn{2}{|c|}{ 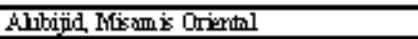 } & \multicolumn{2}{|l|}{ Thiog, Lirmo del Horte } & \multicolumn{2}{|c|}{ Enuz Limborgen Stuloy } \\
\hline & Fennile & $\operatorname{In}\left[h_{3}\right.$ & Fomble & IhIn] & Femnity & Ihlale \\
\hline & CT Reminge & CV Fumbing & DT Fiming & CV Ramints & CV Remiths & CV kimates \\
\hline FWI & 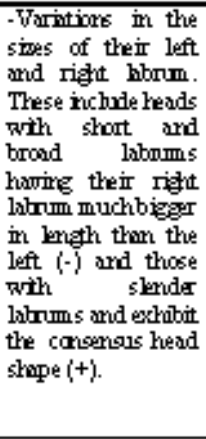 & 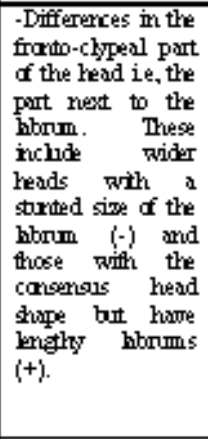 & 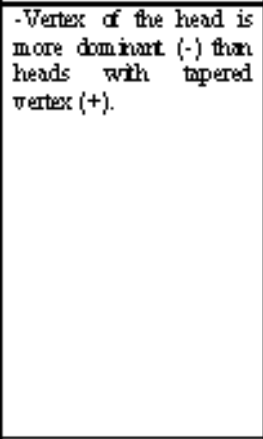 & 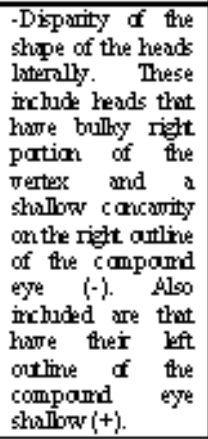 & 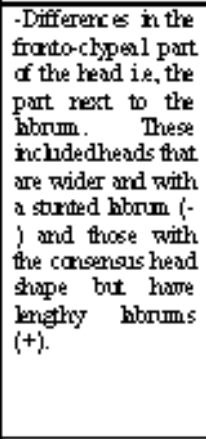 & 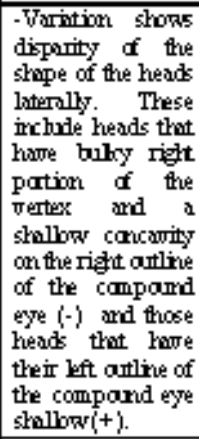 \\
\hline$\overline{\mathrm{FW}}$ & 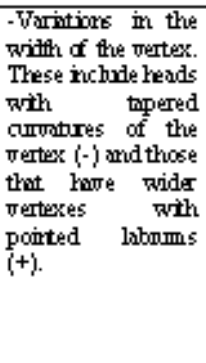 & 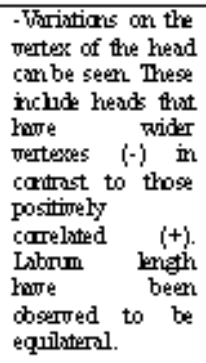 & 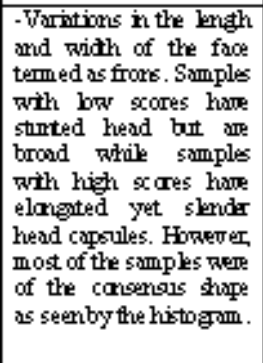 & 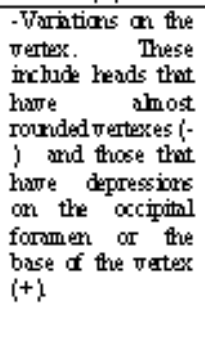 & 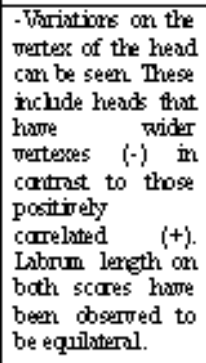 & 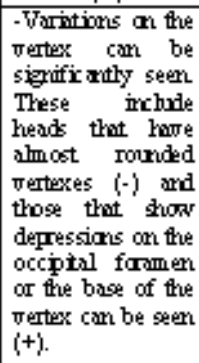 \\
\hline FWS & 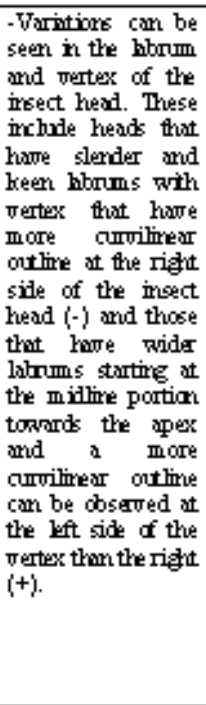 & 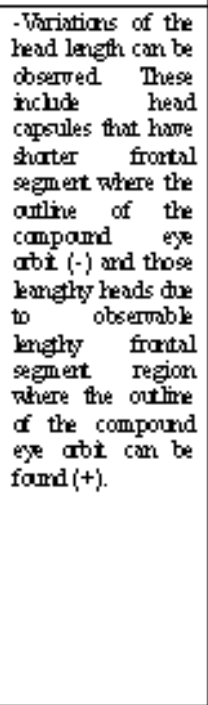 & 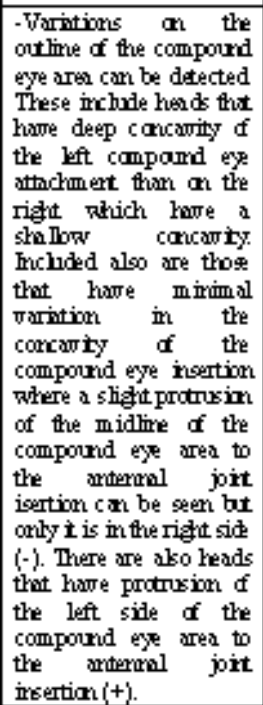 & 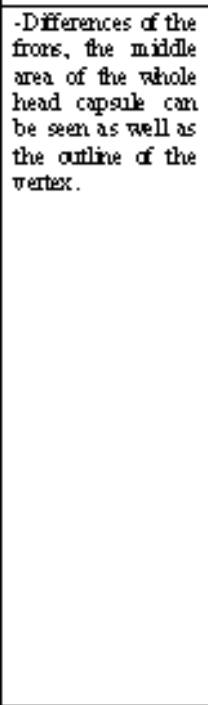 & 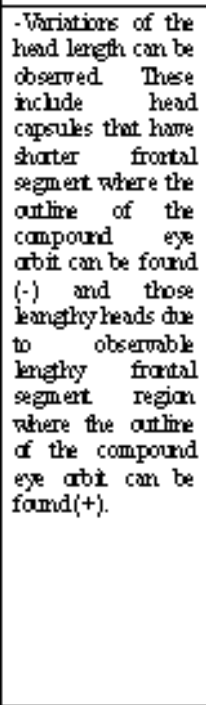 & 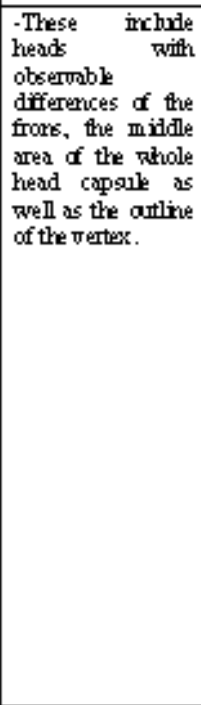 \\
\hline FWT & & & 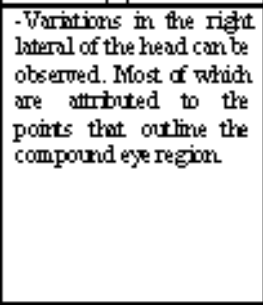 & 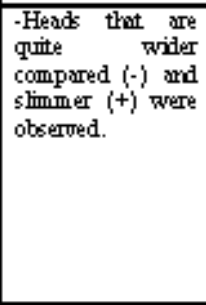 & 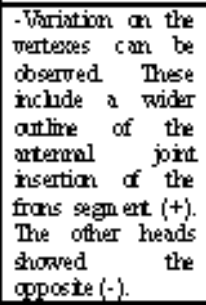 & 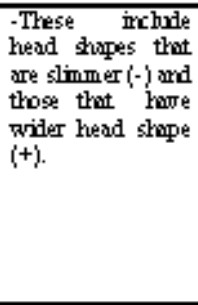 \\
\hline
\end{tabular}




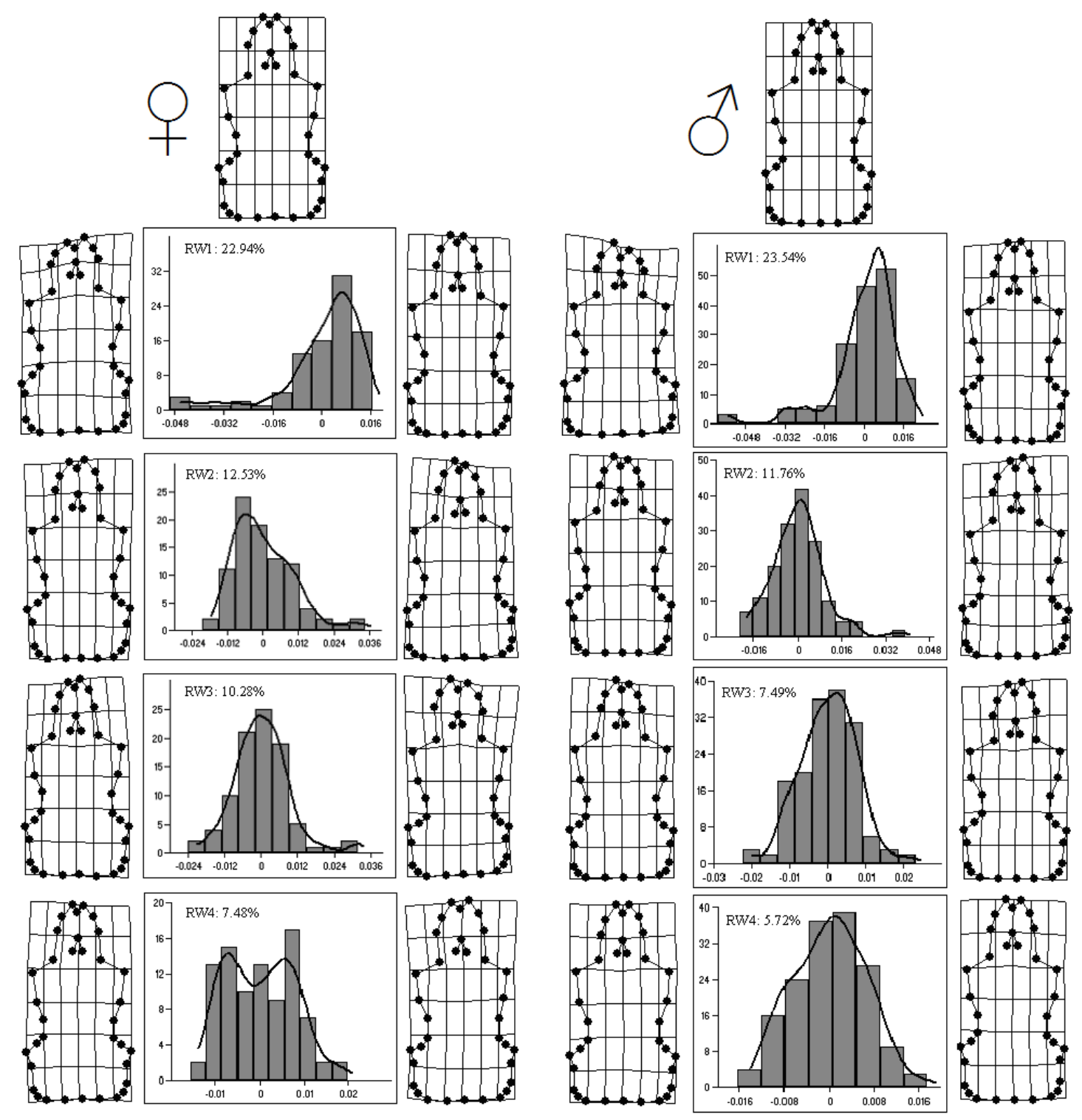

Fig. 5: Summary of the geometric morphometric analysis showing the consensus morphology (uppermost panel) and the variation in head shape among female and male populations of Leptocorisa oratorius (Fabricius) found in Alubijid, Misamis Oriental. 


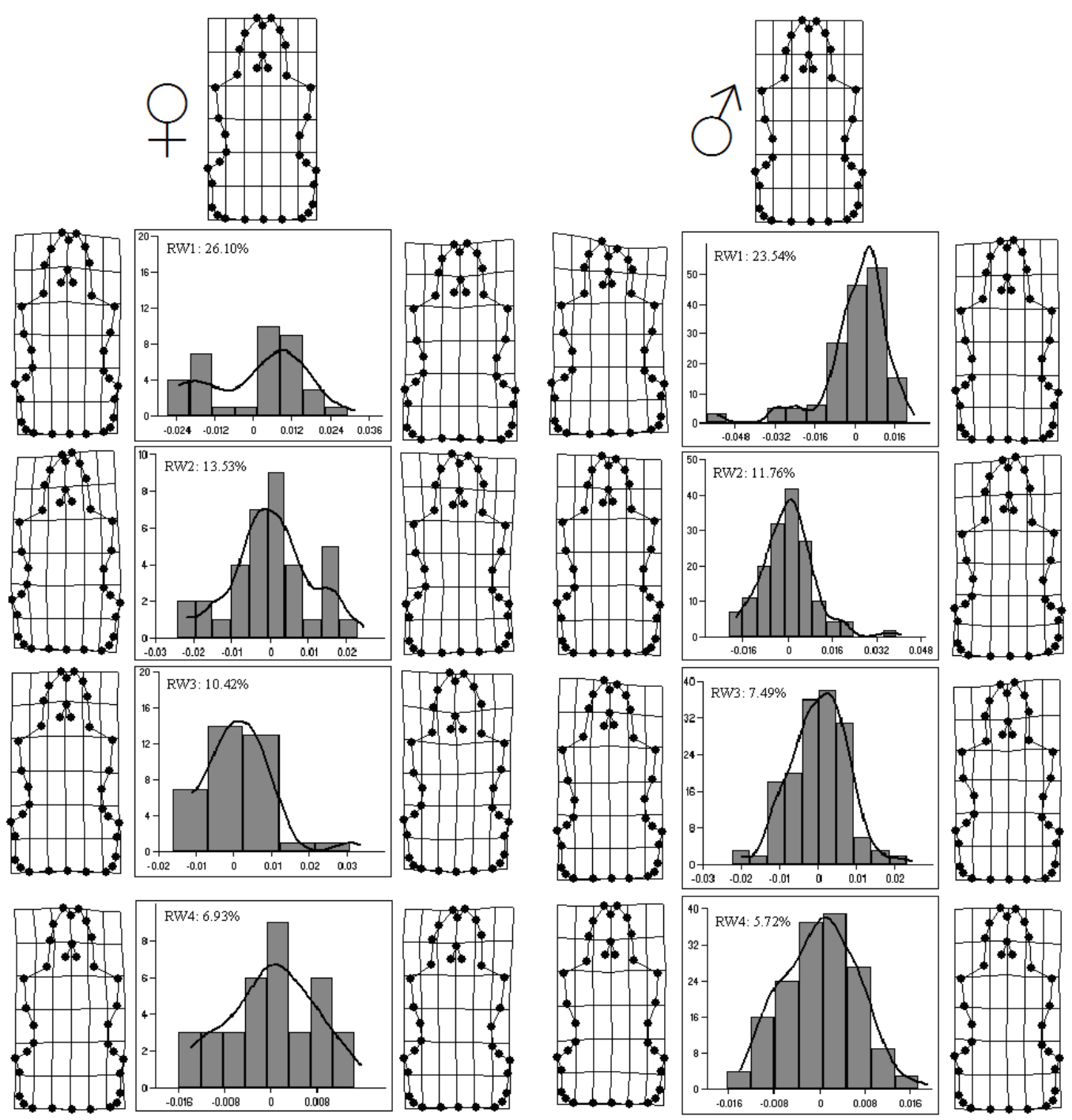

Fig. 6: Summary of the geometric morphometric analysis showing the consensus morphology (uppermost panel) and the variation in head shape among female and male populations of Leptocorisa oratorius (Fabricius) found in Maigo, Lanao del Norte. 


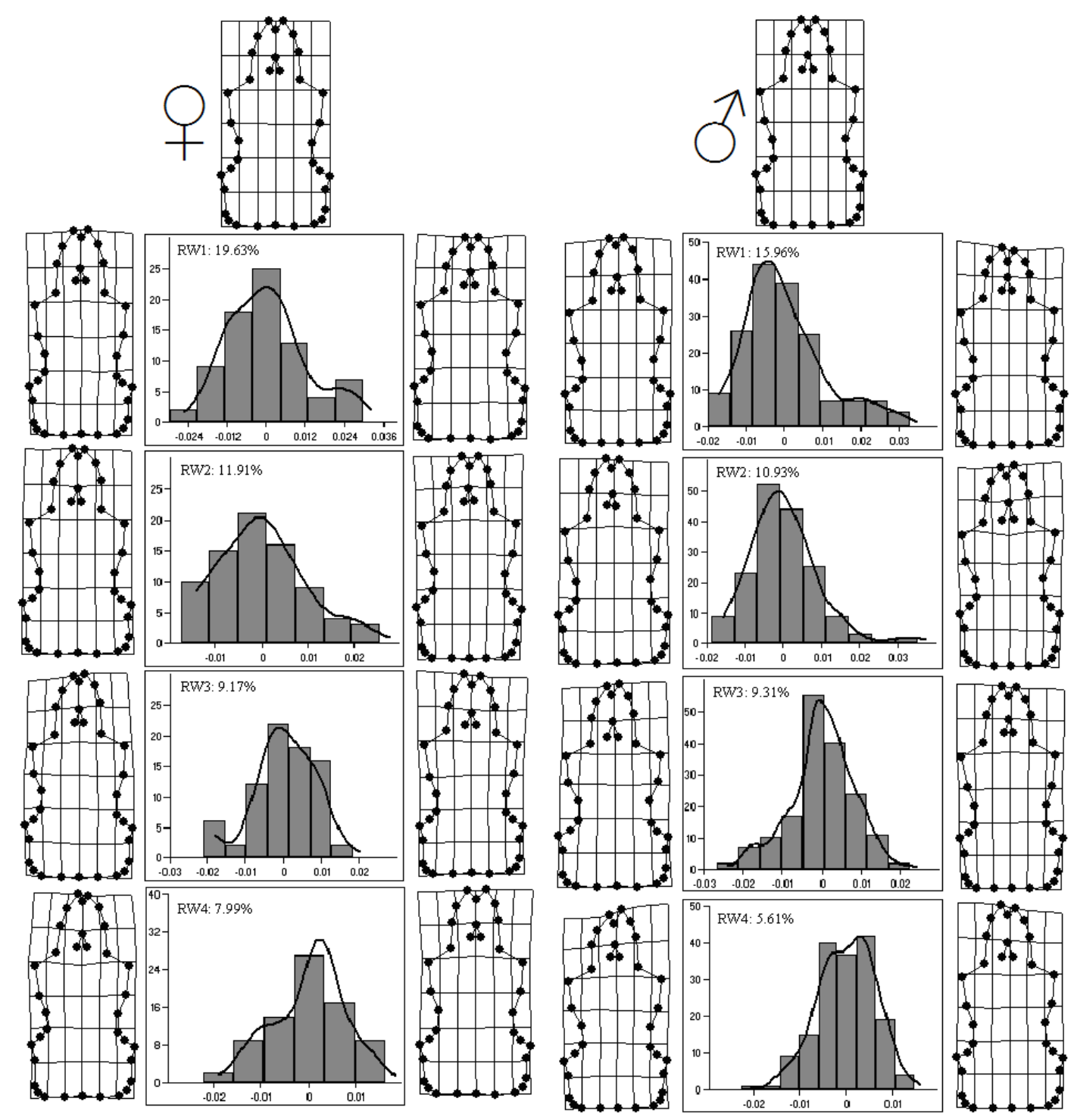

Fig. 7: Summary of the geometric morphometric analysis showing the consensus morphology (uppermost panel) and the variation in head shape among female and male populations of Leptocorisa oratorius (Fabricius) found in Buug, Zamboanga Sibugay.

Since the head is a bilateral structure, sources of shape variation is decomposed into symmetric and asymmetric components (Marquez and Knowles, 2007). Procrustes ANOVA for the study of left-right variation was done (Table 2) (Klingenberg et al., 2002; Leamy, 1984; Palmer and Strobeck, 1992). Results show the deviations of the configurations from the consensus decomposed according to the main effects of individuals, sides (for object symmetry that is reflection), and individuals-by-side interaction (or individuals by-reflections interaction for object symmetry). The main effect of individuals representing the inter-individual variation was significant. Likewise, the main effect of sides (for object symmetry that is reflection) which represents the asymmetric variation called directional asymmetry (DA; one side is systematically different from the other one) was also observed to be significant. The individuals-by-side interaction (or individuals-by-reflections interaction for object symmetry) which quantifies the asymmetric variation within individuals named fluctuating asymmetry (FA; small random differences between the left and right sides in bilateral traits) was also found to be significant. The results 
indicate that there is significant variation in the shape of the head within all populations. Significant degree of asymmetry in the shapes of the head in the populations was also observed although the amount of asymmetry in the shape of the head per population varies significantly within individuals.

Table 2: Results of the procrustes ANOVA conducted on the landmark sets of the head capsule.

\begin{tabular}{|c|c|c|c|c|c|c|}
\hline SAMPLES & & PROI & USTE: & NOVA & & \\
\hline Female & & SS & df & MS & $\mathrm{F}$ & $\mathrm{p}$ \\
\hline \multirow[t]{4}{*}{ Alubijid } & Individuals & 0.0956 & 957 & 0.0001 & 3.0289 & $<0.00$ \\
\hline & Sides & 0.0139 & 33 & 0.0004 & 12.7637 & $<0.00$ \\
\hline & Individuals $\mathrm{x}$ sides & 0.0316 & 957 & 0 & 2.0826 & $<0.00$ \\
\hline & Measurement error & 0.0627 & 3960 & 0 & -- & -- \\
\hline \multirow[t]{4}{*}{ Maigo } & Individuals & 0.0346 & 363 & 0.0001 & 3.1553 & $<0.00$ \\
\hline & Sides & 0.0122 & 33 & 0.0004 & 12.271 & $<0.00$ \\
\hline & Individuals $\mathrm{x}$ sides & 0.011 & 363 & 0 & 1.6606 & $<0.00$ \\
\hline & Measurement error & 0.0288 & 1584 & 0 & -- & -- \\
\hline \multirow[t]{4}{*}{ Buug } & Individuals & 0.0762 & 825 & 0.0001 & 2.9269 & $<0.00$ \\
\hline & Sides & 0.0185 & 33 & 0.0006 & 17.7435 & $<0.00$ \\
\hline & Individuals $\mathrm{x}$ sides & 0.026 & 825 & 0 & 1.5496 & $<0.00$ \\
\hline & Measurement error & 0.0699 & 3432 & 0 & -- & -- \\
\hline Male & & SS & $\mathrm{df}$ & MS & $\mathrm{F}$ & $\mathrm{p}$ \\
\hline \multirow[t]{4}{*}{ Alubijid } & Individuals & 0.1611 & 1716 & 0.0001 & 2.9316 & $<0.00$ \\
\hline & Sides & 0.0228 & 33 & 0.0007 & 21.6208 & $<0.00$ \\
\hline & Individuals $\mathrm{x}$ sides & 0.0549 & 1716 & 0 & 2.103 & $<0.00$ \\
\hline & Measurement error & 0.1065 & 6996 & 0 & -- & -- \\
\hline \multirow[t]{4}{*}{ Maigo } & Individuals & 0.0178 & 198 & 0.0001 & 2.4589 & $<0.00$ \\
\hline & Sides & 0.0048 & 33 & 0.0001 & 3.9739 & $<0.00$ \\
\hline & Individuals $\mathrm{x}$ sides & 0.0072 & 198 & 0 & 1.9475 & $<0.00$ \\
\hline & Measurement error & 0.0173 & 924 & 0 & -- & -- \\
\hline \multirow[t]{4}{*}{ Buug } & Individuals & 0.1459 & 1815 & 0.0001 & 2.7285 & $<0.00$ \\
\hline & Sides & 0.0283 & 33 & 0.0009 & 29.1417 & $<0.00$ \\
\hline & Individuals $\mathrm{x}$ sides & 0.0535 & 1815 & 0 & 1.6143 & $<0.00$ \\
\hline & Measurement error & 0.1349 & 7392 & 0 & -- & -- \\
\hline
\end{tabular}

Discriminant analysis was conducted to deteremine whether the observed variation in the shape of head capsules vary between the three populations of rice bug. This analysis is a standard method for visually confirming or rejecting the hypothesis that two groups are morphologically distinct (Hammer et al., 2001). It also reclassifies the individual of a particular group to another group if the head shape of that individual is similar in shape to the other members' head shapes.

Since sexual dimorphism was observed as confirmed by the canonical variate analysis (Fig. 4), reclassification was done by sex within the three populations. The results were summarized in Table (3). Results show that $81.4 \%$ of the original grouped cases were correctly classified for the females and $71.8 \%$ for the males. The results clearly show significant differences between populations of the rice bugs. 
Table 3: Reclassification of the rice bug, Leptocorisa oratorius (Fabricius) among the three populations.*

\begin{tabular}{|c|c|c|c|c|c|c|}
\hline \multirow[t]{2}{*}{ Male } & & & \multicolumn{4}{|c|}{ PREDICTED GROUP MEMBERSHIP } \\
\hline & & & Alubijid & Maigo & Zamboanga & Total \\
\hline \multirow[t]{6}{*}{ Original } & Count & Alubijid & 77 & 7 & 6 & 90 \\
\hline & & Maigo & 1 & 33 & 2 & 36 \\
\hline & & Zamboanga & 10 & 12 & 56 & 78 \\
\hline & $\%$ & Alubijid & 85.6 & 7.8 & 6.7 & 100 \\
\hline & & Maigo & 2.8 & 91.7 & 5.6 & 100 \\
\hline & & Zamboanga & 12.8 & 15.4 & 71.8 & 100 \\
\hline \multicolumn{7}{|c|}{ *81.4\% of original grouped cases correctly classified. } \\
\hline \multirow[t]{2}{*}{ Female } & & & \multicolumn{4}{|c|}{ PREDICTED GROUP MEMBERSHIP } \\
\hline & & & Alubijid & Alubijid & Alubijid & Alubijid \\
\hline \multirow[t]{6}{*}{ Original } & Count & Alubijid & 19 & 2 & 0 & 21 \\
\hline & & Maigo & 5 & 114 & 40 & 159 \\
\hline & & Zamboanga & 3 & 48 & 117 & 168 \\
\hline & $\%$ & Alubijid & 90.5 & 9.5 & 0 & 100 \\
\hline & & Maigo & 3.1 & 71.7 & 25.2 & 100 \\
\hline & & Zamboanga & 1.8 & 28.6 & 69.6 & 100 \\
\hline
\end{tabular}

*71.8\% of original grouped cases correctly classified.

Results showed variation in the shape of the labrum, vertex, and the concavity where the outline of the compound eye is located. Minimal variations are also seen in other parts such as the parameters of the insertion of the antennal joint. In the analysis of symmetry, it was shown that individual variation were significant. The canonical variate analyis showed that there is significant variations between populations of rice bugs. Also, variation among the sides of each specimen was significant. And lastly, the interaction of both individual and sides provided that there is a significant shape variation of the head within and among populations.

\section{CONCLUSION}

The shape and sizes of different morphological structures reflect their function in nature. These variations in the structure as form and function are said to be interconnected. Organisms exhibit variability in adaptation to environment. One group that exhibit wide range of these characteristics are insects. Insect populations have a wide range of genetic variability that maximizes their fitness in the presence of genetic diversity of host plants. Reduction of insect pest damage and increase in the yield of rice requires the need for an integration of the fundamentals of rice insect taxonomy, its biology and ecology, several various insect control strategies, and development of protocols into a successful rice insect management program.

The claim that the insect head variability reflects their function in nature confirms the fact that rice bugs usually live in the rice fields or on grasses in the vicinity where they feed and multiply during the vegetative phase of the crop. Then, they migrate to the flowering rice fields. Likewise, the variations observed among the populations might also indicate a wide range of genetic variability in rice bugs that maximizes their fitness in the presence of genetic diversity of host plants. According to Ernst Mayr, the famous evolutionary biologist, he stated that variability is inherent in any natural population and is favored by natural selection on account of the 
frequent superiority of heterozygotes and the diversity of the environment (Mayr, 1970). This means that variability is the raw material of adaptibility and long-term survivability - the factor attributable to resistance to several insect pest methods. The knowledge of the variability in the insect pest population and development of several resistant pests, and the development of appropriate strategies would verify the success and failure of pest management strategies. Thus, the overall structure of the insect head variation in this study using geometric morphometrics is an exploration that serve as a model of the insect head shape variability deem informative in the management of insect pests.

\section{REFERENCES}

Adams, D. (1999). Methods for shape analysis of landmark data from articulated structures. Department of Ecology and Evolution, State University of New York at Stony Brook, Stony Brook, NY11794-5245, USA. Evolutionary Ecological Research, 1999, 1: 959-970.

Barrion, A.T. and Litsinger, J.A. (1998). Taxonomy of Insect Pest and their Arthropod Parasites and Predators. Division of Entomology. International Rice Research Institute. P.O. Box 933, Manila, Philippines 1099.

Bookstein, F.L. (1991). Morphometric tools for landmark data. New York: Cambridge University Press.

Caley, K.; Grahame, J. and Mill, P.J. (1995). A geographically based study of shell shape in small rough periwinkles. Hydrobiologia, 309: 181-193.

Conde-Padin, P.; Grahame, J.W. and Rolan-Alvarez, E. (2007). Detecting shape differences in species of the Littorina saxatilis complex by morphometric analysis. Journal of Molluscan Studies, 73: 147-154.

Dale, D. (1994). Insect pests of the rice plant, their biology and ecology. E. A. Heinrichs Biology and management of rice insects 1994: 363-486. Wiley Eastern Limited New Delhi, India.

Dryden, I.L. and Mardia, K.V. (1998). Statistical Shape Analysis. Wiley.

Dvorak, V.; Aytekin, A.M.; Alten, B.; Skarupova, S.; Votypka, J. and Volf, P. (2005). A comparison of the intraspecific variability of Phlebotomus sergenti Parrot, 1917 (Diptera: Psychodidae). Journal of Vector Ecology, (31)2: 229-238.

Frieß, Martin. (2003). An Application of the Relative Warps Analysis to Problems in Human Palaeontoloy - With Notes on Raw Data Quality. Image Anal Stereol, 22: 63-72.

Hammer, Ø.; Harper, D.A.T. and Ryan, P.D. (2001). PAST: Paleontological Statistics Software Package for Education and Data Analysis. Palaeontologia Electronica, 4(1): 9pp. http://palaeo-electronica.org/2001_1/past/issue1_01.htm.

Heinrichs, E.A. (1994). Biology and Management of Rice Insect Pests. Wiley Eastern Limited.

Jahn, G.C.; Domingo, I.; Liberty, M.; Almazan, P. and Pacia, J. (2004). Effect of Rice Bug Leptocorisa oratorius (Hemiptera: Alydidae) on Rice Yield, Grain Quality, and Seed Viability. Journal of Economic Entomology, 97(6): 1923-1927.

Kay, I.R.; Brown, J.D. and Mayer, R. J. (1993). Insecticidal control of Eysarcoris trimaculatus (Distant) (Heteroptera: Pentatomidae) and Leptocorisa acuta (Thunberg) (Heteroptera: Alydidae) on rice in north Queensland, Australia. Crop Protection, 12: 310-314. 
Klingenberg, C.P.; Barluenga, M. and Meyer, A. (2002). Shape analysis of symmetric structures: quantifying variation among individuals and symmetry. Evolution, 56: $1909-1920$.

Leamy, L. J. (1984). Morphometric studies in inbred and hybrid house mice. V. Directional and fluctuating asymmetry. American Naturalist, 123: 579-583.

Losos, J. B. (1990). Ecomorphology, performance capability, and scaling of West Indian Anolis lizards: An evolutionary analysis. Ecol. Monogr., 60: 369-388.

Marquez, E. J. and Knowles, L. L. (2007). SAGE: Symmetry and Asymmetry in Geometric Data. Mammals Division. University of Michigan. Available at: http://www-personal.umich.edu/ emarquez/morph/.

Mayr, E. (1970). Populations, Species and Evolution : An Abridgment of Animal Species and Evolution. Cambridge, Mass: Belknap Press.

Palmer, A.R. and Strobeck, C. (1992). Fluctuating asymmetry as a measure of developmental stability: Implications of non-normal distributions and power of statistical tests. Acta Zoologica Fennica, 191: 57-72.

Panizzi, A. R.; Scaefer C. W. and Toshiro Natuhara. (2000). Heteroptera of Economic Importance. Broad - Headed Bugs (Alydidae). Chapter 10. pp. 321-324.

Pathak, M.D. and Khan Z.R. (1994). Insect Pests of Rice. International Rice Research Institute. International Center of Insect Physiology and Ecology.

Ricklefs, R.E. and Miles, D.B. (1994). Ecological and evolutionary inferences from morphology: An ecological perspective. In Ecological Morphology: integrative Organismal Biology (P.C. Wainwright and S.M. Reilly, eds), pp. 13-41. Chicago, IL: University of Chicago Press.

Rohlf, F. J. (2004). tpsDIG. Version 1.40. N.Y.: Software. State Univ. at Stony Brook. Rohlf, F.J. (2008). tpsRelW ver. 1.46. N.Y.: Software. State Univ. at Stony Brook.

Rohlf, F.J. and Marcus, L. (1993). A revolution in morphometrics. Trends Ecol. Evol., 8(4): 129-32. 